\title{
Documentation of a New Zealand blue whale population based on multiple lines of evidence
}

\author{
Dawn R. Barlow ${ }^{1}$, Leigh G. Torres ${ }^{1, *}$, Kristin B. Hodge ${ }^{2}$, Debbie Steel ${ }^{1}$, \\ C. Scott Baker ${ }^{1,3}$, Todd E. Chandler ${ }^{1}$, Nadine Bott ${ }^{4}$, Rochelle Constantine ${ }^{3}$, \\ Michael C. Double ${ }^{5}$, Peter Gill ${ }^{6}$, Debra Glasgow ${ }^{7}$, Rebecca M. Hamner ${ }^{1,8}$, \\ Callum Lilley ${ }^{4}$, Mike Ogle ${ }^{4}$, Paula A. Olson ${ }^{5,9}$, Catherine Peters ${ }^{10}$, \\ Karen A. Stockin ${ }^{10}$, Christopher T. Tessaglia-Hymes ${ }^{2}$, Holger Klinck ${ }^{2}$ \\ ${ }^{1}$ Marine Mammal Institute, Department of Fisheries and Wildlife, Oregon State University, Newport, OR 97365, USA \\ ${ }^{2}$ Bioacoustics Research Program, Cornell Lab of Ornithology, Cornell University, Ithaca, NY 14850, USA \\ ${ }^{3}$ School of Biological Sciences, University of Auckland, Auckland 1142, New Zealand \\ ${ }^{4}$ New Zealand Department of Conservation, Wellington 6143, New Zealand \\ ${ }^{5}$ Australian Marine Mammal Centre, Australian Antarctic Division, Kingston, TAS 7050, Australia \\ ${ }^{6}$ Blue Whale Study, Narrawong, VIC 3285, Australia \\ ${ }^{7}$ PO Box 98, Paekakariki 5034, New Zealand \\ ${ }^{8}$ Department of Life Sciences, Texas A\&M University - Corpus Christi, Corpus Christi, TX 78412-5802, USA \\ ${ }^{9}$ Southwest Fisheries Science Center NMFS/NOAA, La Jolla, CA 92037, USA \\ ${ }^{10}$ Coastal-Marine Research Group, Institute of Natural and Mathematical Sciences, Massey University, Auckland 0745, \\ New Zealand
}

\begin{abstract}
Species conservation depends on robust population assessment. Data on population abundance, distribution, and connectivity are critical for effective management, especially as baseline information for newly documented populations. We describe a pygmy blue whale Balaenoptera musculus brevicauda population in New Zealand waters with year-round presence that overlaps with industrial activities. This population was investigated using a multidisciplinary approach, including analysis of survey data, sighting records, acoustic data, identification photographs, and genetic samples. Blue whales were reported during every month of the year in the New Zealand Exclusive Economic Zone, with reports concentrated in the South Taranaki Bight (STB) region, where foraging behavior was frequently observed. Five hydrophones in the STB recorded the New Zealand blue whale call type on $99.7 \%$ of recording days (January to December 2016). A total of 151 individuals were photo-identified between 2004 and 2017. Nine individuals were resighted across multiple years. No matches were made to individuals identified in Australian or Antarctic waters. Mitochondrial DNA haplotype frequencies differed significantly between New Zealand ( $\mathrm{n}=53$ individuals) and all other Southern Hemisphere blue whale populations, and haplotype diversity was significantly lower than all other populations. These results suggest a high degree of isolation of this New Zealand population. Using a closed capturerecapture population model, our conservative abundance estimate of blue whales in New Zealand is 718 ( $\mathrm{SD}=433,95 \% \mathrm{CI}=279-1926)$. Our results fill critical knowledge gaps to improve management of blue whale populations in New Zealand and surrounding regions.
\end{abstract}

KEY WORDS: Blue whale $\cdot$ New Zealand $\cdot$ Photo-identification $\cdot$ Abundance $\cdot$ Acoustics $\cdot$ Genetics . Population connectivity $\cdot$ Conservation 


\section{INTRODUCTION}

Efficacy of species conservation efforts is contingent upon robust knowledge of population status. Without information on the spatial and temporal distribution, residency patterns, connectivity, and abundance of populations, conservation efforts will be ineffective. When new species and populations are first described, it is critical that data on these fundamental population parameters are collected to promote ecological understanding, as well as timely and effective management plans.

Blue whales Balaenoptera musculus were severely exploited by the commercial whaling industry (Clapham et al. 1999, Branch et al. 2007, Torres 2013). For example, model estimates indicate that Antarctic blue whale $B$. m. intermedia populations were reduced to less than $1 \%$ of their original population size by commercial whaling (Branch et al. 2004). As a result of such broad scale exploitation, blue whale populations around the world typically remain diminished and are poorly understood. While blue whales are no longer hunted, such reduced population sizes can increase their vulnerability to threats from modern anthropogenic activities.

Three subspecies of blue whales are currently recognized in the Southern Hemisphere: Antarctic B. m. intermedia, pygmy B. m. brevicauda, and Chilean blue whales (recognized as a subspecies by the Society for Marine Mammalogy Committee on Taxonomy, but not yet named; Committee on Taxonomy 2017, Galletti Vernazzani et al. 2017). The pygmy blue whales found in the Indian Ocean and off Australia appear to have diverged from Antarctic blue whales around the last glacial maximum and are genetically, acoustically, and morphologically distinct from Antarctic and Chilean blue whales (Branch et al. 2007, LeDuc et al. 2007, Miller et al. 2014, Attard et al. 2015). Under the International Union for Conservation of Nature (IUCN) Red List of Threatened Species, Antarctic blue whales are classified as 'Critically Endangered' (Reilly et al. 2008), and pygmy blue whales are listed as 'Data Deficient' (Cetacean Specialist Group 1996).

The International Whaling Commission (IWC) has recognized the significant data gaps regarding pygmy blue whale populations by highlighting pygmy blue whale population assessment as a top priority', with an emphasis on estimating the abundance of populations in New Zealand, Indonesia, Australia, and the Southeast Pacific (IWC 2017a). Currently, no reliable abundance estimates exist for pygmy blue whales in any region (Clapham et al.
1999, Attard et al. 2015). Baseline data on population abundance, distribution patterns, and connectivity are fundamental to assess and mitigate impacts from industrial activity and longer-term environmental shifts.

Blue whales (B. m. brevicauda and B. m. intermedia) in New Zealand are currently listed as 'migrant' species under the national threat classification system (Baker et al. 2016). Yet, Torres (2013) hypothesized that the South Taranaki Bight (STB) region of New Zealand is an important foraging ground for blue whales (see Fig. 1) based on (1) opportunistic blue whale sightings in the STB recorded during seismic surveys, (2) observations of blue whales in the STB from Soviet and Japanese whaling records, (3) stranding records of blue whales around New Zealand, and (4) oceanographic studies in the STB documenting regional upwelling events that cause high productivity (Shirtcliffe et al. 1990) and lead to large aggregations of krill Nyctiphanes australis, a known blue whale prey item in the Australasian region (Gill 2002). However, a dedicated study of blue whales in New Zealand had not been conducted. As it is difficult to distinguish between the Antarctic and pygmy blue whale subspecies based on morphology alone, and the distinction is rarely made in sighting and stranding records, Torres (2013) used 'blue whale' to refer to both subspecies and recommended that future work identify the subspecies of blue whale occupying the STB region.

The potential use of the STB region by blue whales is of management concern as the area sustains New Zealand's highest concentration of marine industrial activity. The oil and gas industry has a strong presence in the region, with active extraction platforms and ongoing seismic survey efforts to explore for more oil and gas reserves and new drilling locations (Torres 2013). Vessel traffic frequents the STB, with multiple major ports in the region and the neighboring major shipping channel in the Cook Strait (Rawson \& Riding 2015). The recent approval of the country's first seabed mine in the STB, slated to extract 50 million tons of iron sands per year for a $35 \mathrm{yr}$ period, will likely mean increased anthropogenic pressure on blue whale habitat in the future (Environmental Protection Authority 2017). Due to pressure from the commercial whaling industry, all blue whale populations are likely already depleted (Branch et al. 2007, Torres 2013), and may therefore be especially vulnerable to modern threats from the aforementioned anthropogenic sources.

In this study, we apply a multidisciplinary approach to describe a New Zealand blue whale popu- 
lation, including dedicated surveys, acoustic monitoring, genetic assessment, distribution analysis, and photo-identification. Our objectives are to (1) describe spatial and temporal patterns of blue whale presence within New Zealand waters, (2) quantify patterns of individual resighting events in New Zealand and within the STB region, (3) genetically identify the subspecies of New Zealand blue whales and describe connectivity to other southern hemisphere blue whale populations, and (4) estimate the abundance of blue whales in the STB region and in New Zealand. This baseline population assessment of New Zealand blue whales will contribute to the revision of their national threat classification status and enable informed management decisions for mitigating impacts from industrial activity.

\section{MATERIALS AND METHODS}

\section{Data sources}

\section{Dedicated fieldwork}

Vessel-based surveys for blue whales were conducted in the STB region (Fig. 1) in January and February of 2014, 2016, and 2017. A 14 m jet-propelled catamaran equipped with a flying bridge (height $\sim 4 \mathrm{~m}$ ) for observational work was used as the research platform for the 2014 and 2016 field seasons. In 2017, the research platform was a $19.2 \mathrm{~m}$ vessel outfitted with a comparable flying bridge and equipped with a secondary small rigid-hull inflatable boat for closer approach to the whales. Prior to each survey day, daily images of remotely sensed sea surface temperature and chlorophyll a concentration were assessed to locate areas of upwelled water and high surface productivity; survey tracklines were not standardized, but rather directed toward productive or previously unsurveyed areas.

Survey effort was conducted at vessel speeds of 8 to 12 knots in suitable weather conditions (Beaufort Sea State $<5$ ). During the surveys, one observer was posted on the port and another on the starboard sides of the flying bridge, and additional observers surveyed the entire area. At all whale sightings, survey effort was stopped, and the date, time, and location were recorded. The animal(s) were then approached for photo-identification (photo-ID) effort with concurrent behavioral observation. Photographs of the left and right sides of each blue whale were captured whenever possible for identification of individuals based on unique body pigmentation patterns and dorsal fin shape (Sears et al. 1990). Unmanned aerial system (UAS) flights were also conducted, which allowed for non-disturbing, closer approach and the additional aerial perspective to enhance our observational power for establishing behavior state. Based on surface observations, behavior states were classified as travel, forage, social, rest, or unknown. Travel was defined as directional movement and regular surfacing. Indications of foraging included surface lunges and staying in one area for a prolonged period with irregular surfacings or fluke-out dives. Social behaviors included mother-calf nursing, prolonged coordinated surfacing such as racing, and tactile contact between individuals. Resting behavior consisted of logging near the surface with minimal forward movement. All behaviors that did not fit within these classifications were considered unknown. These data describe blue whale behavior patterns in the STB, but are not necessarily indicative of a behavioral budget.

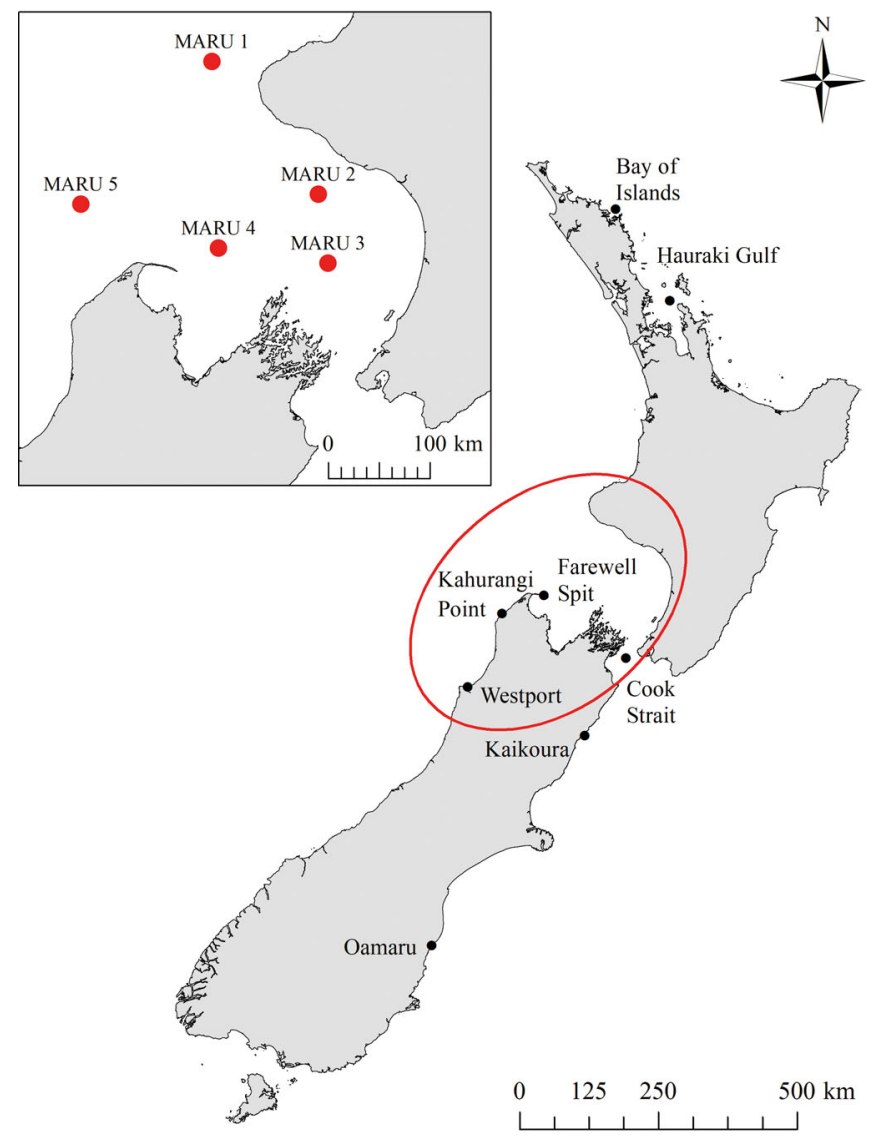

Fig. 1. New Zealand, indicating the location of the South Taranaki Bight (STB) region (marine area within the red circle). Locations of the 5 marine autonomous recording units (MARUs) deployed in the STB region to assess blue whale vocalization patterns are shown in the inset 
Once photo-ID effort was complete, tissue biopsy sampling effort was initiated. Skin and blubber biopsy samples were collected using a lightweight biopsy dart (cutting head size $7 \times 19 \mathrm{~mm}$ ) fired from a Paxarms biopsy rifle (Krutzen et al. 2002). A finemesh $(300 \mu \mathrm{m})$ dip net attached to a long pole was used to collect opportunistic fecal samples from surface waters. Biopsy and fecal samples were stored in sterile containers and frozen at $-20^{\circ} \mathrm{C}$ until genetic analysis.

To assess the spatio-temporal patterns of blue whale vocalizations in the STB region, marine autonomous recording units (MARUs) (Calupca et al. 2000) were deployed at 5 sites (Fig. 1). Each MARU hydrophone had a flat frequency response $( \pm 2.0 \mathrm{~dB})$ in the 15 to $585 \mathrm{~Hz}$ band and recorded continuous acoustic data at a $2 \mathrm{kHz}$ sampling rate with a highpass filter at $10 \mathrm{~Hz}$ and a low-pass filter at $800 \mathrm{~Hz}$. Acoustic data were collected from 23 January to 30 June 2016, and 11 July to 29 December 2016 (MARU refurbishment occurred during the brief interim period). While a New Zealand blue whale call type has previously been documented and described (McDonald 2006), the source level is unknown. The estimated source level for pygmy blue whale song in the eastern Indian Ocean is $179 \pm 2 \mathrm{~dB}$ re $1 \mu \mathrm{Pa}$ at $1 \mathrm{~m}$ (Gavrilov et al. 2011), and the estimated maximum acoustic detection range is 50 to $200 \mathrm{~km}$ (Gavrilov \& McCauley 2013), depending on the recorder capabilities, ambient noise levels, and sound propagation conditions. We expect that the detection range of our hydrophones is comparable with that found by Gavrilov \& McCauley (2013); thus, all acoustic detections of blue whales were from within the New Zealand Exclusive Economic Zone (EEZ).

\section{Opportunistic data sources}

Opportunistic blue whale photographs and sightings were compiled for analysis. Data sources include incidental blue whale sightings confirmed, collated, and administered by the New Zealand Department of Conservation; reports from marine mammal observers during seismic surveys; opportunistic sightings reported during surveys for other marine mammals, and sightings from whale watch vessels (see Table S1 in Supplement 1 at www.int-res.com/articles/suppl/n036 p027_supp/). The blue whale sub-species of these sightings are unknown. Replicate reported sightings were identified and removed from the dataset prior to analysis. Photographs of blue whales suitable for individual identification were provided from 19 sources (see Table S2 in Supplement 1), including contributions from within the New Zealand EEZ (15 sources), from Australian waters (3 sources), and from Antarctic waters (1 source).

\section{Analytical methods}

Distribution of reported sightings

All reported blue whale sightings (from dedicated surveys and opportunistic sources) were compiled to assess their spatial and temporal distribution in New Zealand. The total number of blue whale sighting reports in each month of the year was tabulated within the STB region and within the New Zealand EEZ. Given the non-systematic data collection, this synthesis describes the temporal pattern of sighting reports, not necessarily the temporal distribution of blue whales.

To assess the spatial distribution of sighting reports, all sighting locations within the New Zealand EEZ were plotted in ArcMap 10.4.1 (ESRI 2016) and converted to a point density map using a search radius of $50 \mathrm{~km}$. The resulting map is an assessment of available sighting reports, not a complete depiction of the spatial distribution of blue whales in the New Zealand EEZ.

\section{Acoustics}

Acoustic data were examined for the occurrence of blue whale song (McDonald et al. 2006) using Raven Pro 1.5 (Cornell Lab of Ornithology, Ithaca, USA). While blue whales produce several different vocalizations, song is understood to be produced only by males and likely serves a reproductive function, although the year-round occurrence of blue whale song may suggest a broader function of the call than exclusively reproduction (Oleson et al. 2007). Other blue whale vocalizations, including D-calls, were not analyzed. Data were visually reviewed in consecutive 15 min spectrograms, with a 10 to $250 \mathrm{~Hz}$ frequency bandwidth (512 point Hann window; 50\% overlap). Each recording day was manually reviewed in its entirety by an experienced analyst, and the daily acoustic presence of the New Zealand blue whale call type was annotated for each MARU recording site. Percent monthly presence for each site was normalized for recording effort by dividing the number of days containing the New Zealand blue whale call type by the number of recording days analyzed within the month. 
Photo-identification

Photographs of blue whales from dedicated surveys in the STB region were reviewed and grouped by individual within each sighting event, and individuals were then compared between events. Using standard methods (Sears et al. 1990), individuals were identified using unique body pigmentation patterns and dorsal fin shape. Photograph quality was assigned a rating on a scale of 1 to 5 (with 1 representing the lowest quality and 5 the highest), based on the angle of the photographer to the whale, amount of the whale that was visible in the photograph, sharpness of the image, and glare from the sun. Photographs of quality 1 and 2 were discarded to minimize error in identifying individuals. Using the individuals identified from the dedicated surveys, a discovery curve was generated by plotting the cumulative number of identified individuals versus the cumulative number of days of survey effort. It should be noted that, while for most individuals both sides of the whale were photographed, for some only left-side or right-side photographs were obtained. Therefore, it is possible that some individual whales were counted twice; this can only be reconciled with further data collection in future work.

Subsequently, images of the whales identified during the dedicated surveys within the STB region were compared to the 19 other sources of opportunistically collected photo-ID data (see Table S2). Individuals resighted in multiple years were examined in greater detail, and the sighting locations of resighted animals were plotted in ArcMap 10.4.1.

\section{Genetics}

Biopsy and fecal samples collected in the STB during 2014, 2016, and 2017 were analyzed along with tissue samples held at the New Zealand Cetacean Tissue Archive (NZCeTA) at the University of Auckland. The NZCeTA included samples previously collected from beachcast blue whales (see Fig. 2 from Torres 2013, Table S2 for details) and biopsy samples of 3 live individuals: 1 from the Hauraki Gulf (2006) and 2 from the Cook Strait (2011 and 2013) (Fig. 1). Total genomic DNA was extracted from skin tissue following standard proteinase $\mathrm{K}$ digestion and phenol/chloroform methods (Sambrook et al. 1989), modified for small samples (Baker et al. 1994). Fecal samples were first filtered through a $0.4 \mu \mathrm{m}$ cyclopore polycarbonate track etched membrane filter (GE Healthcare Life Sciences). The filter was trans- ferred to a $2 \mathrm{ml}$ tube and frozen in $800 \mu \mathrm{l}$ of Longmire's buffer (Longmire et al. 1997) until extraction. Total genomic DNA was extracted from the filtered samples using the phenol/chloroform method described above for skin samples with an extended mixing period during the first phenol:chloroform: isoamyl alcohol step to ensure the filter had completely dissolved. Initial attempts to amplify DNA from some fecal samples failed, suggesting the presence of PCR inhibitors. Affected DNA was cleaned with a OneStep ${ }^{\mathrm{TM}}$ PCR inhibitor removal kit (Zymo Research). In some cases, 2 applications were necessary to remove all inhibitors.

A standard DNA profile, including molecular sex, amplification and sequencing of $410 \mathrm{bp}$ of the mitochondrial DNA (mtDNA) control region, and microsatellite genotyping of up to 15 loci, was generated for all samples following methods described by Sremba et al. (2012). An additional 2 microsatellite loci, DlrFCB17 and GATA98, were genotyped following methods described by LeDuc et al. (2007). Control region sequences were visualized and manually reviewed using the program Sequencher v4.6 (Gene Codes Corporation). Individual haplotypes were aligned with previously published blue whale haplotypes (LeDuc et al. 2007, Sremba et al. 2012, TorresFlorez et al. 2014, Attard et al. 2015) downloaded from GenBank. Microsatellite alleles were analyzed using Genemapper v4.0 (Applied Biosystems), and peaks were visually inspected. Samples that amplified at less than 12 loci were considered to be poor quality and were removed from the dataset.

Replicate samples of individual whales were identified using CERVUS v3.0.3 (Kalinowski et al. 2007) and probability of identity $\left(P_{\mathrm{ID}}\right)$ was calculated for pairs of samples showing exact matches. Mismatches of up to 3 loci were allowed to prevent false exclusion due to allelic dropout and other genotyping errors (Waits et al. 2001). Electropherograms from mismatching loci were reviewed and corrected or repeated.

An exact binomial test implemented in Program R version 3.4.0 ( $\mathrm{R}$ Core Team 2017) was used to test whether the sex ratio of males to females differed from 1:1, after removing replicate samples. Arlequin v3.5.1.2 (Excoffier \& Lischer 2010) was used to calculate haplotype diversity and to test for mtDNA haplotype differentiation between (1) STB and NZCeTA samples, and (2) pairwise between the combined New Zealand samples and 3 other populations: Antarctic blue whales in the Southern Ocean $(\mathrm{n}=183$, Sremba et al. 2012), Chilean blue whales in the Southeast Pacific including the Chilean coast $(\mathrm{n}=$ 113, Torres-Florez et al. 2014), and pygmy blue 
whales from the south and west coasts of Australia ( $\mathrm{n}=89$, Attard et al. 2015) that included sequences previously published by LeDuc et al. (2007). The significance of differences in haplotype diversity between the New Zealand dataset and the other blue whale populations was tested using a permutation procedure implemented in Program R, Genetic diversity_diffs v1.0.4 (Alexander et al. 2016). Analysis of molecular variance (AMOVA) implemented in Arlequin was used to estimate mtDNA differentiation of the New Zealand blue whales from the other populations, using both $F_{\mathrm{ST}}$ based on haplotype diversity and $\Phi_{\mathrm{ST}}$ based on nucleotide diversity.

\section{Abundance estimates}

The 3 years of survey effort were used to generate a within-year capture-recapture abundance estimate for the STB region for each year and a conservative abundance estimate for blue whales in New Zealand. A Bayesian closed population model was used, which was fitted using Markov chain Monte Carlo in the R package multimark (McClintock 2015). Models in multimark allow for the inclusion of multiple 'mark types'. Here, our 2 mark types were left- and rightside photographs. It is possible that some individuals were counted twice if left- and right-side photographs were not obtained simultaneously at one encounter, and this is accounted for by the population models implemented in multimark. The use of multimark avoids the need for separate right-side and left-side abundance estimates, and increases our overall sample size. We assumed no behavioral response to the capture events (i.e. captured individuals were no less likely to be re-photographed on a subsequent occasion), equal probability of type 1 and type 2 encounters (i.e. we were equally likely to obtain a left-side photograph as a right-side), a conditional probability of obtaining both mark types simultaneously (i.e. for some animals we had only left-hand or right-hand side photographs, and for some we were able to obtain both during the encounter), and allowed for temporal variation in detection probability.

For each within-year abundance estimate, 3 capture periods were designated as groups of consecutive survey days separated by breaks in survey activity due to poor weather conditions (see Table S3 in Supplement 1). Therefore, if an individual was seen multiple times on the same day or on consecutive days, it was not counted as a resighting to avoid pseudo-replication that would bias the abundance estimate.
An abundance estimate for blue whales in New Zealand was generated using the 3 survey years as 3 separate capture periods (see Table 3). For this estimate, we also used a Bayesian Markov chain Monte Carlo closed-population model in multimark. A complete lack of information on population parameters such as immigration and emigration rates as well as the inability for multimark to compute abundance estimates for open populations incorporating multiple mark types inhibited the application of an openpopulation abundance model. We provide this closedpopulation model abundance estimate for New Zealand blue whales as a conservative estimate, and further justification of this approach is provided in the 'Discussion'. The same detection probability parameters were assumed as for the within-year estimates with the addition of an 'effort' covariate, which accounted for the difference in survey length between the 3 capture events. Survey length was measured by kilometers of survey effort in each year.

\section{RESULTS}

\section{Distribution of sightings}

Three dedicated surveys were conducted in the STB region in 2014 ( $\mathrm{n}=7 \mathrm{~d}$ between 24 January and 3 February), 2016 ( $\mathrm{n}=11 \mathrm{~d}$ between 23 January and 8 February), and 2017 ( $\mathrm{n}=9 \mathrm{~d}$ between 5 and 20 February). This survey effort resulted in a total of 64 blue whale sightings. The most frequently observed known behavior was foraging (32.8\% of sightings), followed by travel $(6.3 \%)$, socializing $(4.7 \%)$, and rest $(0 \%)$. Behavior was unknown for $56.3 \%$ of sightings. Eight mother-calf pairs were observed, including documentation of nursing behavior through UAS (see the video in Supplement 2 at www.int-res.com/ articles/suppl/n036p027_supp/). Combining observations from these dedicated surveys with the opportunistic sightings data, a total of 740 blue whale sightings have been reported in New Zealand waters between 1900 and 2017. Of these, 704 had precise sighting coordinates, while regional sighting locations were provided for the remainder. The sightings without precise location data were used for the temporal distribution assessment, but not for the spatial distribution analysis.

Blue whale sightings were reported during every month of the year (Fig. 2), both in the STB region and elsewhere in the New Zealand EEZ. Fewer sightings were reported during the austral winter months, between May and September. For nearly every 


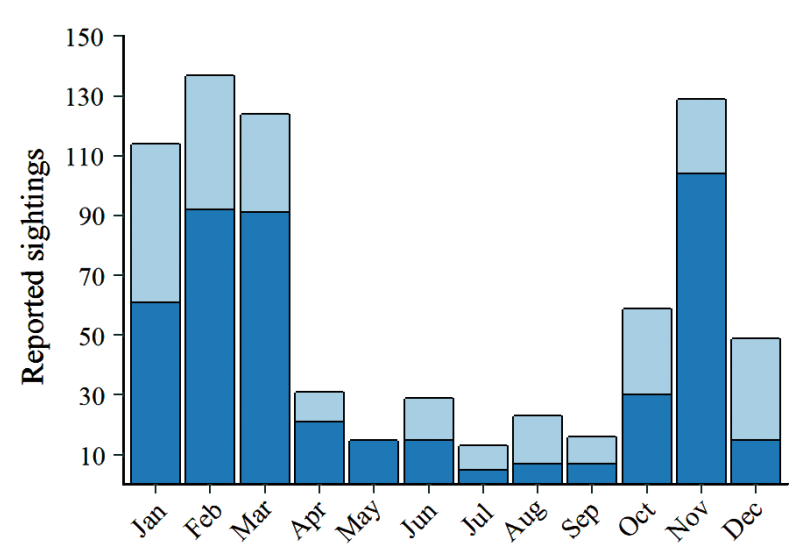

Fig. 2. Blue whale sighting reports by each month of the year between 1900 and 2017, including systematic survey and opportunistic data sources $(n=740)$. (Light blue) All reports from within the New Zealand Exclusive Economic Zone (EEZ), and (dark blue) reports from the South Taranaki Bight (STB) region

month, the majority of reported blue whale sightings within the New Zealand EEZ occurred in the STB region. The spatial distribution of blue whale observations illustrates a predominant concentration of sightings in the STB region (Fig. 3). Additional areas with slightly elevated densities of blue whale sighting reports include the Kaikoura, Hauraki Gulf, and Bay of Islands regions, which could be an artifact of elevated marine observations in these areas (i.e. whale watch and research vessels).

\section{Acoustics}

The total number of recording days ranged between 295 and 331 for each MARU site. New Zealand blue whale calls (Fig. 4; McDonald et al. 2006) occurred regularly at all 5 sites in the STB region (Fig. 5; mean daily occurrence 86.6\% across all sites). Calls occurred most frequently at sites MARU 5 and MARU 1, with $99.7 \%$ and $96 \%$ daily acoustic presence, respectively. All sites had $100 \%$ daily acoustic presence during March, April, and May 2016, and $\geq 90 \%$ daily acoustic presence in June and July. While no blue whale calls occurred at site MARU 3 in January 2016, this hydrophone was only recording for 6 days of the month (Fig. 5). Percent daily acoustic presence of calls was less at sites MARU 2 (44.8\%) and MARU 3 (44.8\%) during February 2016, and for all sites during September 2016 (Fig. 5). No acoustic data were collected at site MARU 4 during December 2016.

No Antarctic blue whale vocalizations (McDonald et al. 2006) were recorded during times when vessel-

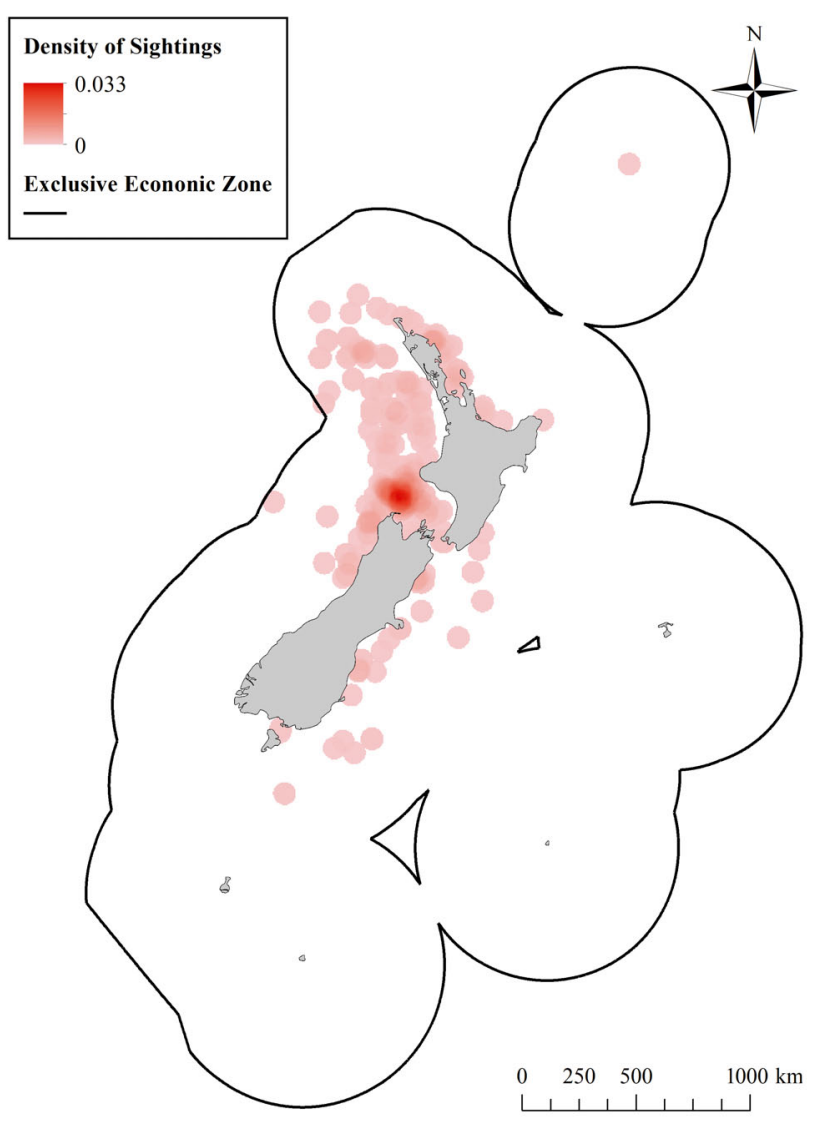

Fig. 3. Spatial distribution of blue whale sighting reports that provided geographic coordinates within the New Zealand Exclusive Economic Zone between the years 1980 and $2017(\mathrm{n}=704)$. Densities are calculated as the number of blue whales per $\mathrm{km}^{2}$ with a $50 \mathrm{~km}$ search radius. A minimum-maximum stretch type with a gamma stretch of 1.5 was applied for visualization

based data collection was underway (January and February 2016). We therefore consider it highly unlikely that any photographs obtained during the dedicated fieldwork in the STB are of Antarctic blue whales.

\section{Photo-identification}

A total of 89 individual blue whales were identified during dedicated surveys in the STB region over the 3 survey years. These identifications included 64 for which both left- and right-side identification photographs were obtained, 12 left-side only IDs, and 13 right-side only IDs; we acknowledge that the true number of unique individuals observed may be slightly lower than 89 . The discovery curve depicts a consistently upward trend and does not appear to be reaching an asymptote (Fig. 6), indicating we are still 


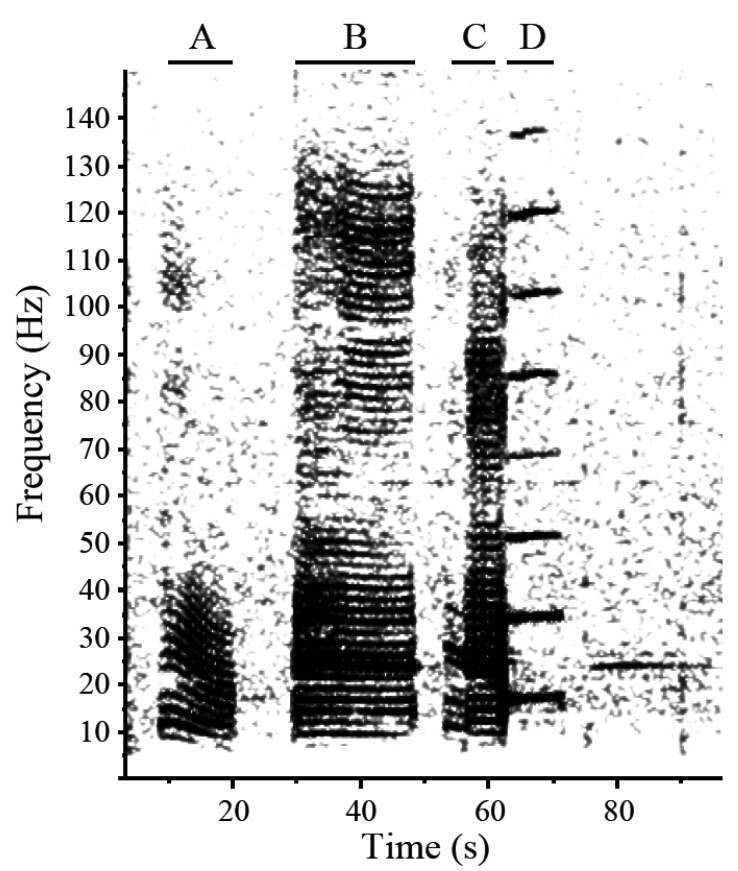

Fig. 4. Spectrogram of New Zealand blue whale call type recorded on 25 February 2016 at marine autonomous recording unit (MARU) 4. Call type consists of 3 pulsed calls (A,B,C), followed by a tonal call (D). Spectrogram visualized with a 1024 point fast Fourier transform, Hann window, $90 \%$ overlap, $0.488 \mathrm{~Hz}$ frequency resolution, and $204 \mathrm{~ms}$ time resolution

in the discovery phase and not yet nearing identification of the entire population.

Opportunistic photographs of New Zealand blue whales identified between 2004 and 2017 were compiled and a total of 322 photographs were deemed suitable for identification and comparison. This op- portunistic photograph dataset yielded 78 sightings for the identification of 62 individuals, and when combined with the STB region survey sightings, a total of 151 unique individuals were identified (93 left- and right-side, 36 left-side only IDs, 22 right-side only IDs). This collection represents the most comprehensive photo-ID catalog of blue whales in New Zealand waters.

Nine blue whales were resighted across multiple years in the New Zealand EEZ (Fig. 7). For all of these inter-annual resightings, at least one of the sightings was in the STB region. For 4 of these resightings, both observations occurred in the STB region within the same monthly period of different years (NZBW004, NZBW018, NZBW008, NZBW023), indicating consistent temporal use of this area by individuals. The maximum number of resightings for an individual was 4 times over a $7 \mathrm{yr}$ period, and this individual (NZBW031) was observed with a calf at 3 out of 4 observations. No blue whales identified anywhere in the New Zealand EEZ matched to any photograph in the Australian collection $(\mathrm{n}=197)$ or Antarctic collection $(\mathrm{n}=65)$.

\section{Genetics}

A total of 72 samples were available for genetic analysis. This included 43 biopsy samples and 14 fecal samples collected in the STB in 2014, 2016 and 2017. Additionally, the NZCeTA contained samples from 12 beachcast whales from around New Zealand

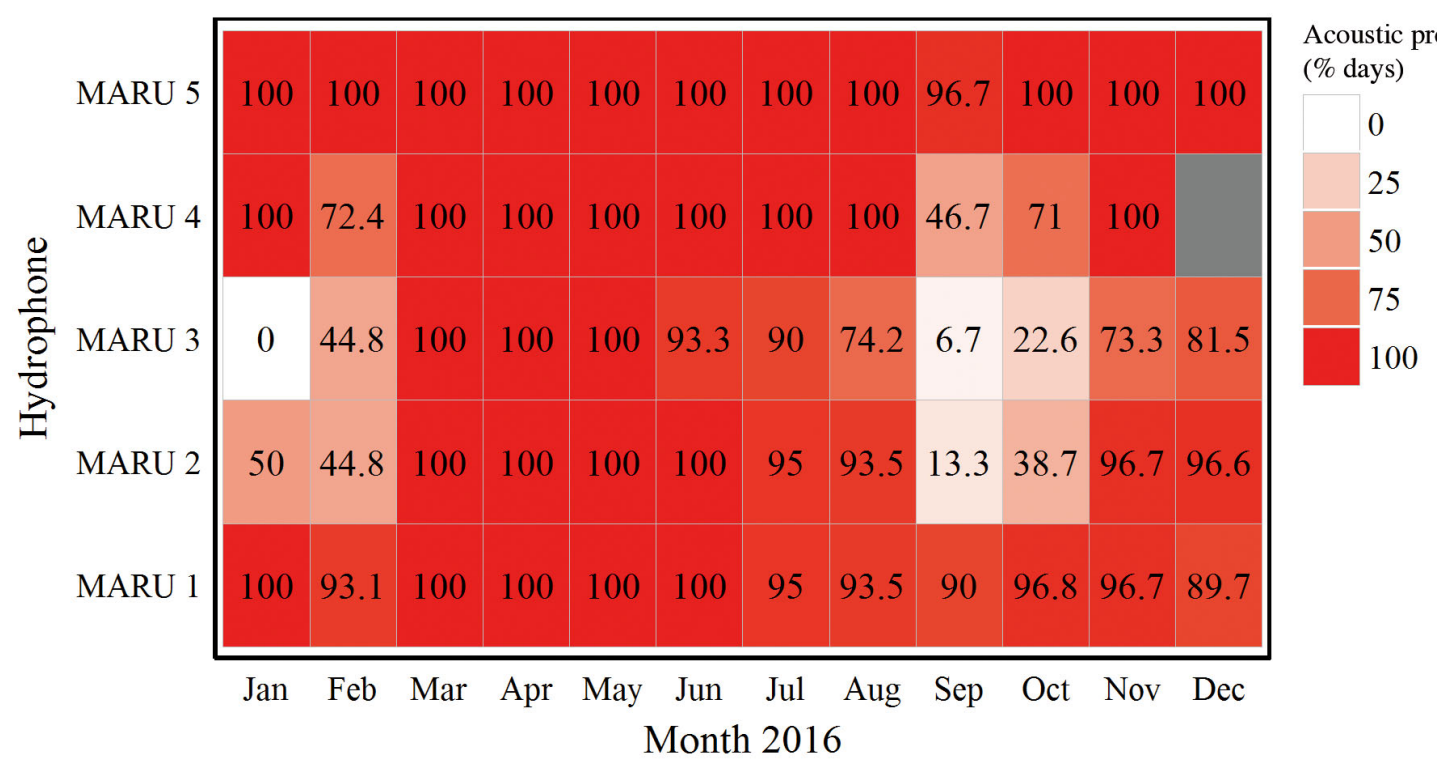

Fig. 5. Percent of recording days with acoustic detection of the New Zealand blue whale call type, by each month of 2016 at each hydrophone location (MARU 1 to 5). No data were collected at site MARU 4 during December 2016 


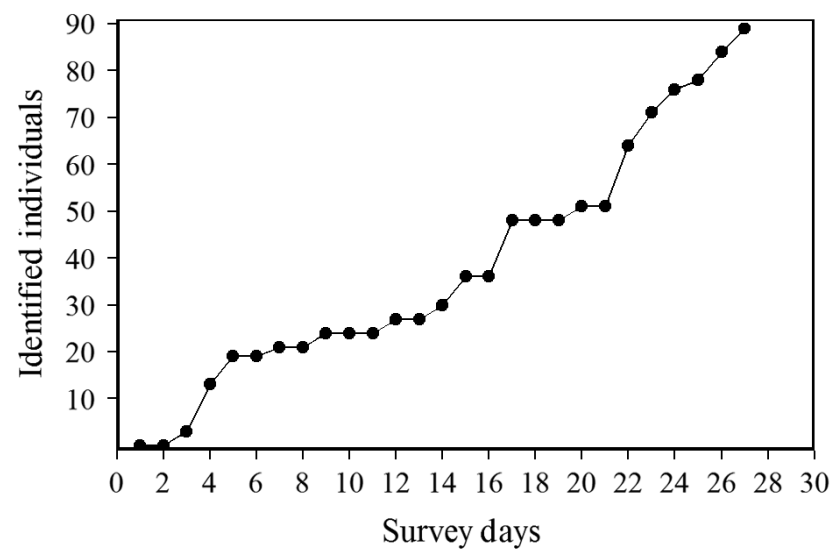

Fig. 6. Blue whale photo-identification discovery curve of the cumulative number of unique individuals identified versus the cumulative number of days of survey effort. Data were derived from dedicated survey effort in the South Taranaki

Bight (STB) region during 2014, 2016, and 2017

and biopsy samples collected from 2 live whales in the Cook Strait and 1 in the Hauraki Gulf. Six of the fecal samples and 2 skin samples collected from beachcast whales failed to amplify for 12 or more loci and were considered poor quality. The 6 poor quality fecal samples were removed from further analysis. As the 2 poor quality skin samples obtained from beachcast whales were collected before any biopsy effort, they represent 2 unique individuals that were not present for potential resampling during survey effort, and as such, they were retained in the genetic dataset.

Genotype matching identified 10 whales sampled multiple times in the STB region by biopsy and/or fecal sample; these samples show sufficiently low $P_{\text {ID }}$ values $\left(1.17 \times 10^{-9}\right.$ to $\left.7.65 \times 10^{-8}\right)$ to support that the matches are not due to random chance. After removing within-year replicates, genotypes were compared between STB individuals and samples from the NZCeTA. This comparison identified 1 individual sampled in the STB in both the 2014 and 2016 field seasons $\left(P_{\mathrm{ID}}=5.63 \times 10^{-9}\right)$. All genotype matches were confirmed by photo-ID. With all replicates removed, the New Zealand blue whale genetic catalogue contains 53 individuals. Of these, 29 individuals are females and 17 are males; the sex could not be determined for 7 individuals due to degradation of the DNA. The sex ratio of 17:29 did not differ significantly from 1:1 (exact binomial test, $\mathrm{p}=0.104)$.

Control region haplotypes were sequenced from 52 individuals, which included all but one of the NZCeTA samples (Table 1). After control region sequences were trimmed to a $410 \mathrm{bp}$ consensus region and compared with published sequences on GenBank,
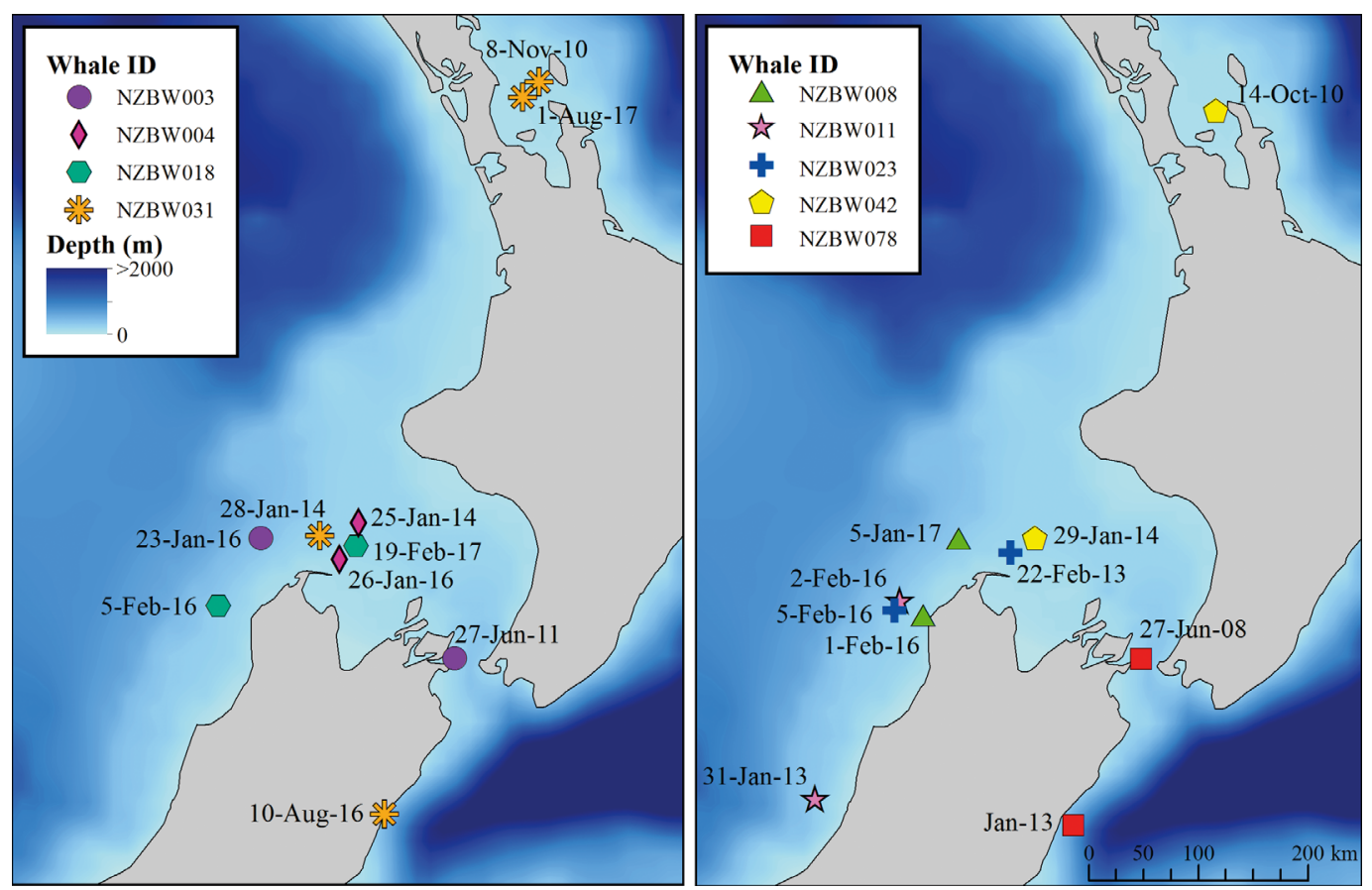

Fig. 7. Inter-annual resighting locations for blue whales in the New Zealand Exclusive Economic Zone. Two panels are used for visual clarity. Note: precise sighting coordinates were not given for NZBW031 in August 2016 or for NZBW078 in January 2013; however, approximate locations were provided. The exact date of the sighting was not provided for NZBW078 in January 2013 
Table 1. Frequencies of mitochondrial DNA haplotypes for individual pygmy blue whales sampled in the South Taranaki Bight (STB) region and from beachcast animals around New Zealand held at the New Zealand Cetacean Tissue Archive (NZCeTA). Haplotype codes follow LeDuc et al. (2007) except for haplotype 15 (Attard et al. 2015) and the 2 newly identified haplotypes (BmuNZ18 and Bmu17NZfl)

\begin{tabular}{|lcccc|}
\hline & GenBank code & STB & NZCeTA & Total NZ \\
\hline Haplotype d & EU093921 & $30^{\mathrm{a}}$ & 10 & 39 \\
Haplotype e & EU093922 & 1 & 2 & 3 \\
Haplotype ii & EU093952 & 2 & 1 & 3 \\
Haplotype mm & EU093956 & 1 & 1 & 1 \\
BmuNZ18 & & 2 & 0 & 2 \\
Haplotype 15 & HQ130731 & 1 & 0 & 1 \\
Bmu17NZf1 & & 1 & 0 & 1 \\
Total & & 38 & 14 & 52 \\
ane sample was heteroplasmic for haplotype d and an \\
undescribed haplotype, and was excluded from further \\
analysis
\end{tabular}

7 haplotypes were identified in the New Zealand dataset: 4 previously described by LeDuc et al. (2007), 1 previously described by Attard et al. (2015), and 2 previously undescribed. The 2 new haplotypes presented here are referred to as BmuNZ18 and Bmu17NZf1. The majority of the samples in the New Zealand dataset $(75 \%)$ were haplotype d (LeDuc et al. 2007).

The haplotype diversity of the New Zealand dataset was $0.406 \pm 0.085(\mathrm{SD})$, which is significantly lower than any of the other blue whale populations tested ( $p<0.001$ for all comparisons; Table 2 ). There was no significant differentiation in mtDNA haplotypes between the STB and NZCeTA collections $\left(F_{\mathrm{ST}}\right.$ $=0.000, p=0.684$ ), so they were combined for comparison to the other areas. The combined New Zealand collection showed highly significant differentiation from the Southern Ocean and Southeast Pacific populations for both $F_{\mathrm{ST}}$ and $\Phi_{\mathrm{ST}}$ (Table 2). The New Zealand collection of samples was most similar to the Australian pygmy blue whale population. Yet, these 2 blue whale populations show a low level of differentiation, indicated by $F_{\mathrm{ST}}(0.04, \mathrm{p}=0.009)$ but not $\Phi_{\mathrm{ST}}(0.013, \mathrm{p}=0.075)$.

\section{Abundance}

The 2017 survey yielded the highest number of individually identified whales, even though the 2016 survey covered the most distance (Table 3 ). Withinyear abundance estimates of blue whales in the STB region were relatively similar for each survey year (Table 3), with a mean of $140(\mathrm{SD}=28)$. Using all survey years of photo-ID captures, our abundance estimate for New Zealand blue whales from a closed population model is 718 ( $\mathrm{SD}=433,95 \% \mathrm{CI}=279$ 1926) individuals. While the uncertainty around this estimate is large, the point estimate of 718 is likely an underestimate of total population size.

\section{DISCUSSION}

Our multidisciplinary study demonstrates that a genetically distinct blue whale population occurs in New Zealand waters year-round. This finding is of significant conservation importance considering the history of exploitation and current anthropogenic threats.

Given that blue whales in New Zealand waters are not solely 'migrant', revision of the current threat classification status of blue whales in New Zealand is warranted. We estimated the abundance of this population to be $718(\mathrm{SD}=433)$ individuals, determined that they are genetically most similar to the pygmy blue whale subspecies Balaenoptera musculus brevicauda found off Australia, described multiple individual resightings within New Zealand waters across multiple years and in multiple seasons, highlighted a lack of photo-ID matches between New Zealand blue whales and photograph collections from neighboring

Table 2. Pairwise comparisons of mitochondrial DNA control region differentiation using haplotype $\left(F_{\mathrm{ST}}\right)$ and nucleotide $\left(\Phi_{\mathrm{ST}}\right)$ diversity $( \pm \mathrm{SD})$ between New Zealand pygmy blue whales and 3 other blue whale populations: the Southern Ocean, the Southeast Pacific, including Chile, Ecuador and Peru, and the Australian population

\begin{tabular}{|lcccccccc|}
\hline Dataset & $\begin{array}{c}\text { Sample } \\
\text { size }\end{array}$ & $\begin{array}{c}\text { No. of } \\
\text { haplotypes }\end{array}$ & $\begin{array}{c}\text { Haplotype } \\
\text { diversity }(h)\end{array}$ & $\begin{array}{c}\text { Nucleotide } \\
\text { diversity }(\pi)\end{array}$ & $F_{\mathrm{ST}}$ & $\mathrm{p}$-value & $\Phi_{\mathrm{ST}}$ & $\mathrm{p}$-value \\
\hline New Zealand & 52 & 7 & $0.406 \pm 0.085$ & $0.001 \pm 0.001$ & - & - & - \\
Southern Ocean & 183 & 52 & $0.969 \pm 0.004$ & $0.014 \pm 0.007$ & 0.257 & $<0.001$ & 0.333 & $<0.001$ \\
Southeast Pacific & 113 & 19 & $0.904 \pm 0.012$ & $0.014 \pm 0.006$ & 0.310 & $<0.001$ & 0.381 & $<0.001$ \\
Australia & 89 & 14 & $0.680 \pm 0.053$ & $0.003 \pm 0.002$ & 0.040 & 0.009 & 0.013 & 0.075 \\
\hline
\end{tabular}


Table 3. Within-year abundance estimates of pygmy blue whales for the South Taranaki Bight region for each survey year

\begin{tabular}{|cccccc|}
\hline Year & $\begin{array}{c}\text { Survey } \\
\text { effort } \\
\text { (akm) }\end{array}$ & $\begin{array}{c}\text { Unique } \\
\text { IDs }\end{array}$ & $\begin{array}{c}\text { Abundance } \\
\text { estimate }\end{array}$ & SD & $\begin{array}{c}95 \% \\
\text { CI }\end{array}$ \\
\hline 2014 & 315 & 22 & 109 & 97 & $29-379$ \\
2016 & 2759 & 26 & 145 & 99 & $47-417$ \\
2017 & 1677 & 42 & 166 & 80 & $75-367$ \\
\hline
\end{tabular}

regions, and documented year-round presence in the STB region where foraging was frequently observed during surveys. These results lead us to hypothesize that this newly documented blue whale population may be largely resident to New Zealand, although we recognize that excursions beyond New Zealand waters may occur. Individual movement data are needed for hypothesis confirmation.

Despite the paradigm that baleen whales migrate seasonally between high-latitude feeding grounds to low-latitude breeding grounds, there are several exceptions (Geijer et al. 2016). It has been noted that blue whales may not always fit this rigid categorization and that migration patterns may also change over time (Calambokidis et al. 2009, LeDuc et al. 2017). Furthermore, it has been established that there is a year-round resident population of Northern Indian Ocean blue whales $B . m$. indica in Sri Lanka (e.g. de Vos et al. 2014) based only on observations of blue whales in the waters surrounding Sri Lanka during every month of the year (Ilangakoon \& Sathasivam 2012). We similarly present evidence of blue whale sighting reports in New Zealand waters during every month of the year, which is corroborated by acoustic detections of the New Zealand blue whale call on $99.7 \%$ of recording days by at least 1 hydrophone during 2016. These findings highlight the importance of relying on applicable scientific data for conservation management rather than on paradigms.

While blue whale sightings and vocalizations were reported during every month of the year, fewer sightings were reported during the winter months, which could indicate that a proportion of the population migrates to other waters, including a yet unknown breeding ground. However, during the winter months with fewer visual sightings, we recorded a high daily acoustic presence in 2016, indicating that decreased visual sightings may be an artifact of observer effort. In contrast, recordings from Australian waters show a stronger seasonal pattern of blue whale acoustic detections, including a drop-off or complete absence during the winter months (Balcazar et al. 2015). Although the breeding and calving locations of this New Zealand population are currently undetermined, our hydrophones often recorded blue whale song, which is thought to be associated with breeding behavior, during every month of the year. Additionally, we observed multiple mother-calf pairs, including documentation of nursing behavior. At this stage we have only assessed acoustic presence, and we recognize that this does not account for call density. Further analysis of our acoustic dataset will elucidate the spatial and temporal occurrence patterns of blue whales in the STB region for a multiple-year recording period.

While the concentration of blue whale sightings in the STB region (Fig. 3) is influenced by both dedicated and seismic survey observer effort in the area, we believe the STB region to be critical habitat for New Zealand blue whales. If Kaikoura, the Hauraki Gulf, and the Bay of Islands were occupied by blue whales with the same frequency as the STB region, sighting reports in these areas would likely be greater due to relatively high observation effort by marine mammal scientists and the whale watching tourism industry. Furthermore, while feeding blue whales have occasionally been reported in the Hauraki Gulf and Kaikoura, oceanographic conditions there are different from those in the STB region, which is characterized by a wind-driven upwelling system that produces a plume of cold, productive water associated with high concentrations of $\mathrm{Nyc}_{\mathrm{C}}$ tiphanes australis (Shirtcliffe et al. 1990, Torres 2013). These oceanographic conditions are unique within New Zealand, and are consistent with welldocumented blue whale habitat in Australia (Gill 2002), Chile (Buchan \& Quiñones 2016), and California (Croll et al. 1998). We therefore posit that, even in the absence of New Zealand-wide systematic survey effort for blue whales, we have substantial evidence to indicate that the STB region is an important area for blue whales within the New Zealand EEZ, particularly for foraging.

The resighting of 9 individual whales between years within the New Zealand EEZ demonstrates site fidelity to New Zealand waters. In addition, Olson et al. (2015) reported one other photo-identification match between years, sighted in the Cook Strait and Oamaru (Fig. 1). Of all these inter-annual resightings, at least one of the sightings was made in the STB region (Fig. 7), further emphasizing the likely importance of the region for blue whales in New Zealand. It is also noteworthy that 3 of the interannual resightings were made in different seasons, 
indicating that at least some individuals make use of the region in both winter and summer.

Genetically, our samples of New Zealand blue whales are most similar to the Australian pygmy blue whales, but differ significantly in haplotype frequencies and diversity. We described 2 new mtDNA haplotypes in the New Zealand population, and the genetic samples are characterized by very low haplotype diversity. This is significantly lower than that of the pygmy blue whale population found in southern Australia that was described as having the lowest genetic diversity of any blue whale population (Attard et al. 2015). As hypothesized by Attard et al. (2015) for the southern Australian pygmy blue whale population, the low genetic diversity of the New Zealand population may reflect a relatively recent founding event. While there was significant differentiation for $F_{\mathrm{ST}}$ based on haplotype diversity, there was no significant differentiation for $\Phi_{\mathrm{ST}}$ based on nucleotide diversity between the New Zealand and Australian populations. This indicates that the New Zealand population is most closely related to the Australian population, and likely corroborates the hypothesis of a more recent founding event as it takes longer for population separation to be reflected in $\Phi_{\mathrm{ST}}$. The low genetic diversity makes these populations potentially vulnerable to future climate change and other anthropogenic impacts (Attard et al. 2015). The vulnerability of the New Zealand population may be exacerbated by their year-round occupancy of the STB region, where they are frequently exposed to anthropogenic activities.

The IWC has prioritized the need for population assessments of pygmy blue whales (IWC 2017a). We present the first abundance estimate for any pygmy blue whale population to date. Although our conservative abundance estimate for pygmy blue whales in New Zealand is based only on photographs captured during dedicated survey effort in the STB region, we consider this estimate representative because (1) the majority of all reported blue whale sightings occurred in the STB region (Fig. 2), (2) individuals reoccur in the STB region across multiple years, with some evidence of individual movement between the STB region and other parts of New Zealand (Fig. 7), (3) no matches have been made between individual blue whales identified in New Zealand and those identified in Australia or Antarctica, and (4) the New Zealand population has significant genetic differentiation from all other known southern hemisphere blue whale populations. In the absence of any known immigration/emigration between New Zealand and other regions, this last point also justifies our applica- tion of a closed population model. However, we recognize that there are several caveats that must accompany this population abundance estimate. The New Zealand blue whale call has infrequently been recorded outside New Zealand waters (in Tonga and eastern Australia; Balcazar et al. 2015). We also acknowledge that births and deaths likely occurred between 2014 and 2017 creating some degree of bias in the estimate. However, this bias is expected to be minimal given the short duration of the study period relative to the low pregnancy rates (Lockyer 1984) and high survival probabilities for blue whales (Ichihara 1966). The rates of individual movement between the STB and other areas of New Zealand are not well understood at this time, and therefore could not be accounted for in our abundance model. The result of the closed population model using our 3 survey years as discrete capture periods, therefore, represents a conservative abundance estimate $(\mathrm{N}=718$, $\mathrm{SD}=433$ ) for the blue whale population occupying New Zealand waters. This New Zealand estimate is qualified as a Category 2 abundance estimate under the standards set by the IWC, described as 'an underestimate, suitable for 'conservative' management but not necessarily reflective of total abundance' (IWC $2017 b)$. The upward trend of the discovery curve indicates that we are not yet nearing full identification of the whole population. Additionally, the low rate of resightings resulted in wide confidence intervals around the estimate, which may be reduced with subsequent years of data collection and analysis.

In this study, we document a unique New Zealand blue whale population through a comprehensive population assessment that determined evidence of yearround presence, individual resightings across years, and genetic differentiation from other regions. These multidisciplinary results align and lead us to hypothesize that this blue whale population may be mostly resident within New Zealand waters. The concentration of blue whales in the STB region is of significant management importance due to the high industrial presence in this area. Further investigation into potential space-use conflict between blue whales and industrial activity such as seismic surveys, oil and gas drilling and extraction, seabed mining, and vessel traffic is warranted. A vital first step in any impact assessment is baseline information on population distribution, connectivity, and abundance, which we have provided here. We recommend that subsequent analyses build on these findings to investigate blue whale spatial and temporal habitat use patterns and assess the potential cumulative effects of industrial activity on the behavior and health of the population. 
Acknowledgements. Funding for this project was provided by The Aotearoa Foundation, The New Zealand Department of Conservation, The National Geographic Society Waitt Foundation, The Marine Mammal Institute at Oregon State University, The National Oceanographic and Atmospheric Administration's Cooperative Institute for Marine Resources Studies (NOAA/CIMRS), Greenpeace New Zealand, OceanCare, Kiwis Against Seabed Mining, The International Fund for Animal Welfare, The Thorpe Foundation, and an anonymous donor. The project was accomplished through the dedicated work and support of many individuals including the crew of the RV 'Star Keys' (Western Work Boats) and the RV 'Ikatere' (National Institute of Water and Atmospheric Research), Kathy Minta and Minda Stiles from Oregon State University, Ian Angus, Laura Boren, Hannah Hendriks, Andrew Lamason, and Dave Lundquist from the New Zealand Department of Conservation, and Edward James Moore III from the Bioacoustics Research Program at Cornell University. Blue whale sightings and photo-identification contributions are also recognized from Blue Planet Marine, the Ministry for Primary Industries, OMV, Petroleum Geo-Services, Dolphin Safari, Whale Watch Kaikoura, and the following individuals: Olive Andrews, Haley Baxter, Aneke Bowker, Jaime Brown, Deanna Clement, Sonja Clemens, Tony Crocker, Eric de Boer, Nico de la Brosse, Sarah Dwyer, Deanna Elvines, Viraj Gamage, Sarah Gardner, Dan Govier, Theresa Kirchner, Krista Hupman, Helen McConnell, Don Neale, Terry Visser, Jody Weir, and Roger Williams.

\section{LITERATURE CITED}

Alexander A, Steel D, Hoekzema K, Mesnick SL and others (2016) What influences the worldwide genetic structure of sperm whales (Physeter macrocephalus)? Mol Ecol 25: 2754-2772

Attard CRM, Beheregaray LB, Jenner KCS, Gill PC and others (2015) Low genetic diversity in pygmy blue whales is due to climate-induced diversification rather than anthropogenic impacts. Biol Lett 11:20141037

* Baker CS, Slade RW, Bannister JL, Abernethy RB and others (1994) Hierarchical structure of mitochondrial DNA gene flow among humpback whales Megaptera novaeangliae, world-wide. Mol Ecol 3:313-327

Baker CS, Chilvers BL, Childerhouse S, Constantine R and others (2016) Conservation status of New Zealand marine mammals, 2013. New Zealand threat classification series 14. New Zealand Department of Conservation, Wellington

Balcazar NE, Tripovich JS, Klinck H, Nieukirk SL, Mellinger DK, Dziak RP, Rogers TL (2015) Calls reveal population structure of blue whales across the Southeast Indian Ocean and the Southwest Pacific Ocean. J Mammal 96: 1184-1193

Branch TA, Matsuoka K, Miyashita T (2004) Evidence for increases in Antarctic blue whales based on Bayesian modelling. Mar Mamm Sci 20:726-754

Branch TA, Stafford KM, Palacios DM, Allison C and others (2007) Past and present distribution, densities and movements of blue whales Balaenoptera musculus in the Southern Hemisphere and northern Indian Ocean. Mammal Rev 37:116-175

Buchan SJ, Quiñones RA (2016) First insights into the oceanographic characteristics of a blue whale feeding ground in northern Patagonia, Chile. Mar Ecol Prog Ser 554:183-199

* Calambokidis J, Barlow J, Ford JKB, Chandler TE, Douglas $A B$ (2009) Insights into the population structure of blue whales in the Eastern North Pacific from recent sightings and photographic identification. Mar Mamm Sci 25: 816-832

Calupca TA, Fristrup KM, Clark CW (2000) A compact digital recording system for autonomous bioacoustic monitoring. J Acoust Soc Am 108:2582

Cetacean Specialist Group (1996) Balaenoptera musculus ssp. brevicauda. IUCN Red List Threat Species 1996: e.T2479A9449204. http://dx.doi.org/10.2305/IUCN.UK. 1996.RLTS.T2479A9449204.en (accessed 15 August 2017)

* Clapham PJ, Young SB, Brownell RL Jr (1999) Baleen whales: conservation issues and the status of the most endangered populations. Mammal Rev 29:37-60

Committee on Taxonomy (2017) List of marine mammal species and subspecies. Society for Marine Mammalogy, www.marinemammalscience.org (accessed 15 August 2017)

* Croll DA, Tershy BR, Hewitt RP, Demer DA and others (1998) An integrated approach to the foraging ecology of marine birds and mammals. Deep Sea Res II 45: 1353-1371

\% de Vos A, Pattiaratchi CB, Harcourt RG (2014) Inter-annual variability in blue whale distribution off southern Sri Lanka between 2011 and 2012. J Mar Sci Eng 2:534-550

Environmental Protection Authority (2017) Decision on marine consents and marine discharge application: TransTasman Resources Limited. Extracting and processing iron sand within the South Taranaki Bight. New Zealand Government, Wellington. https://www.epa.govt.nz/assets/ Uploads/Documents/Marine-Activities-EEZ/Activities/ TTRL-Marine-Consent-Decision-EEZ000011-FINALversion.pdf

ESRI (Environmental Systems Research Institute) (2016) ArcGIS Desktop: Release 10. Environmental Systems Research Institute, Redlands, CA

* Excoffier L, Lischer HEL (2010) Arlequin suite ver 3.5: A new series of programs to perform population genetics analyses under Linux and Windows. Mol Ecol Resour 10: 564-567

Galletti Vernazzani B, Jackson JA, Cabrera E, Carlson CA, Brownell RL (2017) Estimates of abundance and trend of Chilean blue whales off Isla de Chiloé, Chile. PLOS ONE 12:e0168646

Gavrilov AN, McCauley RD (2013) Acoustic detection and long-term monitoring of pygmy blue whales over the continental slope in southwest Australia. J Acoust Soc Am 134:2505-2513

*Gavrilov AN, McCauley RD, Salgado-Kent C, Tripovich J, Burton C (2011) Vocal characteristics of pygmy blue whales and their change over time. J Acoust Soc Am 130: 3651-3660

*Geijer CKA, Notarbartolo di Sciara G, Panigada S (2016) Mysticete migration revisited: Are Mediterranean fin whales an anomaly? Mammal Rev 46:284-296

Gill P (2002) A blue whale (Balaenoptera musculus) feeding ground in a southern Australian coastal upwelling zone. J Cetacean Res Manag 4:179-184

Ichihara T (1966) The pygmy blue whale, Balaenoptera musculus brevicauda, a new subspecies from the Antarctic. In: Norris KS (ed) Whales, dolphins and porpoises. University of California Press, Berkeley, CA, p 79-113 
Ilangakoon AD, Sathasivam K (2012) The need for taxonomic investigations on Northern Indian Ocean blue whales (Balaenoptera musculus): implications of yearround occurrence off Sri Lanka and India. J Cetacean Res Manag 12:195-202

IWC (International Whaling Commission) (2017a) Report of the Scientific Committee Annex H : Report of the subcommittee on other Southern Hemisphere whale stocks. IWC, Bled

IWC (International Whaling Commission) (2017b) Report of the Scientific Committee Annex Q : Report of the ad hoc working group on abundance estimates, stock status and international cruises. IWC, Bled

Kalinowski ST, Taper ML, Marshall TC (2007) Revising how the computer program CERVUS accommodates genotyping error increases success in paternity assignment. Mol Ecol 16:1099-1106

Krutzen M, Barre LM, Moller LM, Heithaus MR, Simms C, Sherwin WB (2002) A biopsy system for small cetaceans: darting success and wound healing in Tursiops spp. Mar Mamm Sci 18:863-878

LeDuc RG, Dizon AG, Goto M, Pastene L and others (2007) Patterns of genetic variation in Southern Hemisphere blue whales and the use of assignment test to detect mixing on the feeding grounds. J Cetacean Res Manag 9:73-80

LeDuc RG, Archer FI, Lang AR, Martien KK and others (2017) Genetic variation in blue whales in the eastern Pacific: implication for taxonomy and use of common wintering grounds. Mol Ecol 26:740-751

Lockyer C (1984) Review of baleen whale (Mysticeti) reproduction and implications for management. Rep Int Whal Comm Spec Issue 6:27-50

Longmire JL, Maltbie M, Baker RJ (1997) Use of 'lysis buffer' in DNA isolation and its implications for museum collections. Occas Pap Mus Tex Tech Univ 163:1-3

McClintock BT (2015) multimark: An R package for analysis of capture-recapture data consisting of multiple 'noninvasive' marks. Ecol Evol 5:4920-4931

McDonald MA (2006) An acoustic survey of baleen whales off Great Barrier Island, New Zealand. N Z J Mar Freshw Res 40:519-529

McDonald MA, Mesnick SL, Hildebrand JA (2006) Biogeographic characterisation of blue whale song worldwide: using song to identify populations. J Cetacean Res Manag 8:55-65

Miller BS, Collins K, Barlow J, Calderan S and others (2014) Blue whale vocalizations recorded around New Zealand: 1964-2013. J Acoust Soc Am 135:1616-1623

Oleson EM, Calambokidis J, Burgess WC, McDonald MA,

Editorial responsibility: Mike Noad,

Gatton, Queensland, Australia
LeDuc CA, Hildebrand JA (2007) Behavioral context of call production by eastern North Pacific blue whales. Mar Ecol Prog Ser 330:269-284

Olson PA, Ensor P, Olavarria C, Bott N and others (2015) New Zealand blue whales: residency, morphology, and feeding behavior of a little-known population. Pac Sci 69: 477-485

R Core Team (2017) R: a language and environment for statistical computing. R Foundation for Statistical Computing, Vienna

Rawson A, Riding J (2015) South Taranaki Bight marine traffic study. Prepared for Trans-Tasman Resources by Marico Marine. Marico Marine NZ, Wellington. https://www.epa. govt.nz/assets/FileAPI/proposal/EEZ000011/Applicantsproposal-documents-Application-documents/Report27-Marico-Marine-Traffic-Study-December-2015.pdf (accessed 27 March 2017)

Reilly SB, Bannister JL, Best PB, Brown M and others (2008) Balaenoptera musculus ssp. intermedia (errata version published in 2016). IUCN Red List Threat Species 2008: e.T41713A98837960. http://dx.doi.org/10.2305/IUCN.UK. 2008.RLTS.T41713A10543676.en (accessed 4 August 2017)

Sambrook J, Fritsch EF, Maniatis T (1989) Molecular cloning: a laboratory manual. Cold Spring Harbor Laboratory Press, Cold Spring Harbor, NY

Sears R, Williamson MJ, Wenzel FW, Bérubé M, Gendron D, Jones P (1990) Photographic identification of the blue whale (Balaenoptera musculus) in the Gulf of St. Lawrence, Canada. Rep Int Whal Comm Spec Issue 12: 335-342

Shirtcliffe TGL, Moore MI, Cole AG, Viner AB, Baldwin R, Chapman B (1990) Dynamics of the Cape Farewell upwelling plume, New Zealand. N Z J Mar Freshw Res 24:555-568

* Sremba AL, Hancock-Hanser B, Branch TA, LeDuc RL, Baker CS (2012) Circumpolar diversity and geographic differentiation of mtDNA in the Critically Endangered Antarctic blue whale (Balaenoptera musculus intermedia). PLOS ONE 7:e32579

* Torres LG (2013) Evidence for an unrecognised blue whale foraging ground in New Zealand. N Z J Mar Freshw Res 47:235-248

Torres-Florez JP, Hucke-Gaete R, LeDuc R, Lang A and others (2014) Blue whale population structure along the eastern South Pacific Ocean: evidence of more than one population. Mol Ecol 23:5998-6010

Waits LP, Luikart G, Taberlet P (2001) Estimating the probability of identity among genotypes in natural populations: cautions and guidelines. Mol Ecol 10:249-256

Submitted: September 25, 2017; Accepted: March 22, 2018 Proofs received from author(s): April 30, 2018 